\title{
Miller Table Company: A Profit Analysis Case Integrating Managerial Accounting, Microeconomics And Marketing
}

Louise Miller, Robert Morris University, USA

\begin{abstract}
This paper describes a unique integrative business case appropriate for use in a managerial accounting course or other business courses related to economics or marketing. The case describes a scenario in which a managerial accountant is assisting in business decisions relating to factors influencing the profitability of a small manufacturing operation. Students are asked to optimize profits for company operations given information concerning costs, quality, and marketing options.
\end{abstract}

Keywords: Profit Optimization; Marketing; Microeconomics

\section{INTRODUCTION}

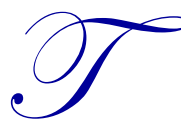

his paper describes a business case that is based in Microsoft Excel and demonstrates an analysis that assists with managerial decision-making. Ringelstein (2009) points out that the Excel spreadsheet, as a teaching instrument, motivates students and provides them with the opportunity to learn computing skills as well as accounting techniques. "The use of computer technology assists students to gain a personal understanding of the issues and to develop a specific set of skills that are useful for management accountants" (Ringelstein, 2009). Spreadsheets encourage students to develop critical analytical skills that are in demand by employers. Cory and Pruske (2012) conclude that certain accounting-related skills and topics in accounting curriculums are essential. Spreadsheet software (Excel) was ranked as the number one critical skill desired by employers.

Spreadsheets have evolved as critical tools for business analysis. There are many examples in current business literature of applications built in spreadsheets to support analysis of marketing decisions. B $\varnothing$ and Hammervoll (2010) illustrate an MS Excel spreadsheet decision tool. They describe the development and application of a valuable decision support tool to ensure appropriate pricing of services in the wholesale grocery industry. Coles and Rowley (1996) discuss the potential use of spreadsheets as decision-support systems. They illustrate some of the models that can be easily built with modern spreadsheet packages, including models to support what-if or scenario analysis, sensitivity analysis, goal seeking and optimization. The Excel-based decision support model presented by Fischer et al. (2012) illustrates that it is possible to determine near-optimal marketing budgets. Their model accounts for marketing dynamics and trade-offs with respect to marketing effectiveness and profit contribution. These examples illustrate the pervasiveness of spreadsheet modeling in business and its importance in business curriculums.

\section{CASE DESCRIPTION}

The case described here is an example of a simple optimization model that can give students insight into several concepts in multiple business disciplines. It can be used as a demonstration or an assignment in managerial accounting, marketing, or economics courses. This integrative case illustrates profit analysis for a small table manufacturing operation and requires the students to build the analysis in Microsoft Excel and use elementary calculus to find the optimal selling price of a table. The case describes a scenario in which a managerial accountant 
is assisting the Chief Financial Officer (CFO) of the manufacturing firm in a business decision related to the quality of the tables, the advertising level and the location strategy. Students are asked to optimize profits for a product line given information concerning costs and the marketing options. This case gives students insight into the calculus of optimization used in business problems. This case can also be used in a microeconomics course to illustrate the concepts of price determination in a competitive market. It can be used to illustrate that in a competitive market, the price for a good will vary until it settles at a point where the quantity demanded by consumers at a certain price will equal the quantity supplied by producers, resulting in an economic equilibrium for price and quantity. This case can also be used in marketing courses to illustrate that effective pricing strategies and analysis of various options that affect demand can greatly affect profits and ultimately affect competitive advantage. Intelligent pricing decisions require a strong understanding of consumer demand, competing strategies and effective promotional approaches. "Marketing budget decisions are critical and should be fact-based rather than intuitive" (Fischer et al., 2012).

Figure 1 illustrates the spreadsheet that is provided for the students which gives instructions for the case. Discrete variables for the quality of the tables, the advertising level and the location strategy are described and formulas for variable and fixed expenses are provided. A table that the students can use for making calculations is provided. (Note that only the column headings in Table 1 are supplied for the students.) Students are asked to determine the equation for profit and then to determine the optimal set of discrete variables and selling price that results in maximum profit. They are required to use simple calculus to find optimal prices instead of the Excel Solver add-in or other methods. 


\section{Miller Table Company Case}

You are the management accountant of the Miller Table Company.

The CFO of Miller Table Company launches a project to determine how to maximize the profit of a particular line of tables they sell. He asks the sales and marketing department to analyze prior sales and produce a formula for number of tables sold based on the price of the tables and the following factors:

The QUALITY OF THE tables:

$Q=1 \quad$ Standard Quality

$Q=2$ Above Average Quality

$\mathbf{Q}=3$ High Quality

The ADVERTISING LEVEL:

$A=1$ LOW

$A=2$ MEDIUM

$A=3$ HIGH

The LOCATION STRATEGY of the tables:

$X=1 \quad$ Discount Stores only

$X=2 \quad$ Department stores

$X=3 \quad$ Discount stores and Online

The marketing department presents this formula to the CFO:

NUMBER OF PAIRS OF tables SOLD PER YEAR, $N=48000+2000(A+Q+X)-500 P$ where $P$ is the price of a table.

(Notice that this formula makes sense intuitively because the more you advertise,

the more you sell, but the higher the price, the less you sell.)

The CFO asks you to use this formula to figure out how to maximize profit. So your job is to select the quality level of the tables, the appropriate advertising level, the best location strategy, and the optimal price of your tables.

In other words, pick $Q, A, X$, and the price for the maximum profit possible.

You also are given the following about costs:

The variable cost per table is given by: $V=5(Q+3)$

The total fixed expenses per year is given by: $F=15000 A+5000 X$

Your tasks are:

1) First, find an equation that specifies the profit for Miller.

Remember, profit (net operating income) is given by:

PROFIT = TOTAL REVENUE - FIXED EXPENSES - TOTAL VARIABLE EXPENSES

(Your equation should give profit in terms of $Q, A, X$, and $P$.)

2) Next, suppose the CFO tells you that he wants to set the price of the tables at $\$ 60.00$.

He also wants to sell only above average or high quality tables.

For that price, what $Q, A$, and $X$ will give Miller the maximum profit??

Hint: Make a table with 8 columns (started for you below) for each possible combination and the resulting profit

3) Finally, the CFO tells you that he wants you to determine the best price and which $Q, A$, and $X$ options to select that will result in the maximum profit.

Hint: The profit equation is an upside-down parabola.

Use simple calculus to find the price that gives the maximum profit. Add columns 9 and 10 below.

TABLE 1: FOR CALCULATING PROFIT AND OPTIMAL PROFIT FOR EACH COMBINATION

\begin{tabular}{|c|c|c|c|c|c|c|c|c|c|}
\hline \multirow{3}{*}{$\begin{array}{l}\text { Quality } \\
\text { Q }\end{array}$} & \multirow{3}{*}{$\begin{array}{c}\text { Advertising } \\
\text { A }\end{array}$} & \multirow{3}{*}{\begin{tabular}{|c|c|c|} 
Location \\
$\mathrm{X}$
\end{tabular}} & \multirow{2}{*}{\multicolumn{5}{|c|}{\begin{tabular}{|c|} 
Enter a price per table to calculate PROFIT column $\$ 68.00$ \\
Results calculated at the price above \\
\end{tabular}}} & \multirow{3}{*}{$\begin{array}{l}\text { OPTIMAL } \\
\text { PRICE } \\
\end{array}$} & \multirow{3}{*}{\begin{tabular}{|c|} 
PROFIT \\
AT OPTIMAL \\
PRICE \\
\end{tabular}} \\
\hline & & & & & & & & & \\
\hline & & & Total Var Cost & Fixed Cost & Num Sold & Sales & Profit & & \\
\hline & & & & & & & & & \\
\hline & & & & & & & & & \\
\hline & & & & & & & & & \\
\hline & & & & & & & & & \\
\hline
\end{tabular}

Figure 1: Student Problem Spreadsheet 


\section{CASE SOLUTION}

We start with the profit equation given in the problem:

PROFIT $=$ Total Revenue - Fixed Expenses - Total Variable Expenses

For $\mathrm{P}=$ Price, $\mathrm{N}=$ number of tables sold, $\mathrm{F}=$ fixed expenses, and $\mathrm{V}=$ variable expense per table,

PROFIT $=$ PN $-\mathrm{F}-$ VN

Students are asked to produce the profit equation for this company in terms of quality, advertising, and location. They should substitute the formulas for expenses and number of tables sold provided in the problem. Given that $\mathrm{V}=5(\mathrm{Q}+3), \mathrm{N}=48000+2000(\mathrm{~A}+\mathrm{Q}+\mathrm{X})-500 \mathrm{P}$, and $\mathrm{F}=15000 \mathrm{~A}+5000 \mathrm{X}$, the profit equations becomes:

$\mathrm{PROFIT}=\mathrm{P}(48000+2000(\mathrm{~A}+\mathrm{Q}+\mathrm{X})-500 \mathrm{P})-15000 \mathrm{~A}-5000 \mathrm{X}-(5(\mathrm{Q}+3))(48000+2000(\mathrm{~A}+\mathrm{Q}+\mathrm{X})-500 \mathrm{P})$

This results in the following quadratic equation:

PROFIT $=-500 \mathrm{P}^{\wedge} 2+\mathrm{P}[55,500+2000 \mathrm{~A}+2000 \mathrm{X}+4500 \mathrm{Q}]+[-45000 \mathrm{~A}-35,000 \mathrm{X}-270,000 \mathrm{Q}-10,000 \mathrm{Q}-$ $\left.10,000 Q^{\wedge} 2-720,0000\right]$

Next, the derivative of the profit equation is taken with respect to price:

$\mathrm{dPROFIT} / \mathrm{dP}=-1000 \mathrm{P}+55,500+2000 \mathrm{~A}+2000 \mathrm{X}+4500 \mathrm{Q}$

To find the price $\mathrm{P}_{\mathrm{opt}}$ that optimizes profit, this is set equal to zero:

$0=-1000 \mathrm{P}_{\mathrm{opt}}+55,500+2000 \mathrm{~A}+2000 \mathrm{X}+4500 \mathrm{Q}$

Solving for the optimal price $\mathrm{P}_{\mathrm{opt}}$ :

$\mathrm{P}_{\mathrm{opt}}=55.5+2 \mathrm{~A}+2 \mathrm{X}+4.5 \mathrm{Q}$

This equation illustrates that the optimal price is a function of the quality of the tables, the advertising level and the location strategy. This equation is used for the "Optimal Price" column in the profit table. Students can then use the values in this column to create a column for the profits that result from the optimal prices. This column identifies the optimal price of a table that results in maximum profit for each possible combination of quality, advertising level and the location strategy. Of course, Microsoft Excel's Solver add-in can also be used to solve for the optimal price for each combination (row), but this would be a tedious repetitive process and would not give students insight into the calculus of optimization required in the solution of this problem. However, an instructor can use the spreadsheet as an opportunity to illustrate the use of Solver for optimization problems in business.

The final step in the solution of the problem is to examine the "Profit at Optimal Price" column and identify the row with the highest profit. The optimal price, quality, advertising level and location strategy values in this row are the answers that should be reported to the CFO of the company. The solution is shown in Table 2. For this problem, the optimal price is $\$ 72.00$ and the optimal discrete variables are standard quality tables, high advertising level, and a location strategy of selling in a combination of discount stores and online. 


\begin{tabular}{|c|c|c|c|c|c|c|c|c|c|}
\hline & & & & \multicolumn{4}{|c|}{ TABLE 2: CASE SOLUTION } & & \\
\hline & & & \multicolumn{5}{|c|}{ Enter a price per table to calculate PROFIT column $\$ 68.00$} & \multirow{3}{*}{$\begin{array}{c}\text { OPTIMAL } \\
\text { PRICE }\end{array}$} & \multirow{3}{*}{$\begin{array}{c}\text { PROFIT } \\
\text { AT OPTIMAL } \\
\text { PRICE }\end{array}$} \\
\hline \multirow{2}{*}{\begin{tabular}{|c|} 
Quality \\
Q
\end{tabular}} & \multirow{2}{*}{$\begin{array}{c}\text { Advertising } \\
\text { A }\end{array}$} & \multirow{2}{*}{$\begin{array}{c}\text { Location } \\
X\end{array}$} & \multicolumn{5}{|c|}{ Results calculated at the price above } & & \\
\hline & & & Total Var Cost & Fixed Cost & Num Sold & Sales & Profit & & \\
\hline 1 & 1 & 1 & $\$ 400,000$ & $\$ 20,000$ & 20,000 & $\$ 1,360,000$ & $\$ 940,000$ & $\$ 64.00$ & $\$ 948,000$ \\
\hline 1 & 1 & 2 & $\$ 440,000$ & $\$ 25,000$ & 22,000 & $\$ 1,496,000$ & $\$ 1,031,000$ & $\$ 66.00$ & $\$ 1,033,000$ \\
\hline 1 & 1 & 3 & $\$ 480,000$ & $\$ 30,000$ & 24,000 & $\$ 1,632,000$ & $\$ 1,122,000$ & $\$ 68.00$ & $\$ 1,122,000$ \\
\hline 1 & 2 & 1 & $\$ 440,000$ & $\$ 35,000$ & 22,000 & $\$ 1,496,000$ & $\$ 1,021,000$ & $\$ 66.00$ & $\$ 1,023,000$ \\
\hline 1 & 2 & 2 & $\$ 480,000$ & $\$ 40,000$ & 24,000 & $\$ 1,632,000$ & $\$ 1,112,000$ & $\$ 68.00$ & $\$ 1,112,000$ \\
\hline 1 & 2 & 3 & $\$ 520,000$ & $\$ 45,000$ & 26,000 & $\$ 1,768,000$ & $\$ 1,203,000$ & $\$ 70.00$ & $\$ 1,205,000$ \\
\hline 1 & 3 & 1 & $\$ 480,000$ & $\$ 50,000$ & 24,000 & $\$ 1,632,000$ & $\$ 1,102,000$ & $\$ 68.00$ & $\$ 1,102,000$ \\
\hline 1 & 3 & 2 & $\$ 520,000$ & $\$ 55,000$ & 26,000 & $\$ 1,768,000$ & $\$ 1,193,000$ & $\$ 70.00$ & $\$ 1,195,000$ \\
\hline 1 & 3 & 3 & $\$ 560,000$ & $\$ 60,000$ & 28,000 & $\$ 1,904,000$ & $\$ 1,284,000$ & $\$ 72.00$ & $\$ 1,292,000$ \\
\hline 2 & 1 & 1 & $\$ 550,000$ & $\$ 20,000$ & 22,000 & $\$ 1,496,000$ & $\$ 926,000$ & $\$ 68.50$ & $\$ 926,125$ \\
\hline 2 & 1 & 2 & $\$ 600,000$ & $\$ 25,000$ & 24,000 & $\$ 1,632,000$ & $\$ 1,007,000$ & $\$ 70.50$ & $\$ 1,010,125$ \\
\hline 2 & 1 & 3 & $\$ 650,000$ & $\$ 30,000$ & 26,000 & $\$ 1,768,000$ & $\$ 1,088,000$ & $\$ 72.50$ & $\$ 1,098,125$ \\
\hline 2 & 2 & 1 & $\$ 600,000$ & $\$ 35,000$ & 24,000 & $\$ 1,632,000$ & $\$ 997,000$ & $\$ 70.50$ & $\$ 1,000,125$ \\
\hline 2 & 2 & 2 & $\$ 650,000$ & $\$ 40,000$ & 26,000 & $\$ 1,768,000$ & $\$ 1,078,000$ & $\$ 72.50$ & $\$ 1,088,125$ \\
\hline 2 & 2 & 3 & $\$ 700,000$ & $\$ 45,000$ & 28,000 & $\$ 1,904,000$ & $\$ 1,159,000$ & $\$ 74.50$ & $\$ 1,180,125$ \\
\hline 2 & 3 & 1 & $\$ 650,000$ & $\$ 50,000$ & 26,000 & $\$ 1,768,000$ & $\$ 1,068,000$ & $\$ 72.50$ & $\$ 1,078,125$ \\
\hline 2 & 3 & 2 & $\$ 700,000$ & $\$ 55,000$ & 28,000 & $\$ 1,904,000$ & $\$ 1,149,000$ & $\$ 74.50$ & $\$ 1,170,125$ \\
\hline 2 & 3 & 3 & $\$ 750,000$ & $\$ 60,000$ & 30,000 & $\$ 2,040,000$ & $\$ 1,230,000$ & $\$ 76.50$ & $\$ 1,266,125$ \\
\hline 3 & 1 & 1 & $\$ 720,000$ & $\$ 20,000$ & 24,000 & $\$ 1,632,000$ & $\$ 892,000$ & $\$ 73.00$ & $\$ 904,500$ \\
\hline 3 & 1 & 2 & $\$ 780,000$ & $\$ 25,000$ & 26,000 & $\$ 1,768,000$ & $\$ 963,000$ & $\$ 75.00$ & $\$ 987,500$ \\
\hline 3 & 1 & 3 & $\$ 840,000$ & $\$ 30,000$ & 28,000 & $\$ 1,904,000$ & $\$ 1,034,000$ & $\$ 77.00$ & $\$ 1,074,500$ \\
\hline 3 & 2 & 1 & $\$ 780,000$ & $\$ 35,000$ & 26,000 & $\$ 1,768,000$ & $\$ 953,000$ & $\$ 75.00$ & $\$ 977,500$ \\
\hline 3 & 2 & 2 & $\$ 840,000$ & $\$ 40,000$ & 28,000 & $\$ 1,904,000$ & $\$ 1,024,000$ & $\$ 77.00$ & $\$ 1,064,500$ \\
\hline 3 & 2 & 3 & $\$ 900,000$ & $\$ 45,000$ & 30,000 & $\$ 2,040,000$ & $\$ 1,095,000$ & $\$ 79.00$ & $\$ 1,155,500$ \\
\hline 3 & 3 & 1 & $\$ 840,000$ & $\$ 50,000$ & 28,000 & $\$ 1,904,000$ & $\$ 1,014,000$ & $\$ 77.00$ & $\$ 1,054,500$ \\
\hline 3 & 3 & 2 & $\$ 900,000$ & $\$ 55,000$ & 30,000 & $\$ 2,040,000$ & $\$ 1,085,000$ & $\$ 79.00$ & $\$ 1,145,500$ \\
\hline 3 & 3 & 3 & $\$ 960,000$ & $\$ 60,000$ & 32,000 & $\$ 2,176,000$ & $\$ 1,156,000$ & $\$ 81.00$ & $\$ 1,240,500$ \\
\hline
\end{tabular}

\section{CONCLUSION}

Optimization problem solutions are critically important for the analysis of decisions related to resource allocations and the analysis of future profit projections. This paper described a unique management accounting case appropriate for use in marketing courses, introductory microeconomics courses, or introductory or upper level managerial accounting courses. A spreadsheet model is used to assist in decisions concerning factors influencing the profitability of a small table manufacturing operation. This case involves the analysis of uncertainties in factors affecting future profits and is an illustration of Excel-based analysis that provides useful information for decisionmakers. This case illustrates to students that in real-world complex business operations, decisions regarding uncertainties and the allocation of resources are important and affect the profit outcomes of a business.

The specific learning objectives (functional competencies) of this case are for students to:

1. Understand the importance of the use of spreadsheets to create and evaluate decision-support models.

2. Understand that profit optimization analysis can be a valuable decision-making process for business managers concerned with future business success.

3. Understand that in real-world manufacturing operations, decisions regarding quality and the allocation of resources affect the profit outcomes of a company.

4. Gain an understanding of the fundamentals of the calculus of optimization used in business problems.

5. Understand that in a competitive market, there is an economic equilibrium for price and quantity demanded and that effective pricing strategies and analysis of various options that affect demand can greatly affect profits. 
By mapping the case activities to functional competencies and directly measuring multiple outcomes in these activities, these competencies can be assessed in the course as prescribed in the business department's assessment plan.

\section{AUTHOR INFORMATION}

Dr. Louise Miller has a PhD in Management Science, an MBA and a BS degree in Electrical Engineering. Her research interests include accounting information systems and the integration of technology into accounting education. Dr. Miller also enjoys painting, web site design and programming. She teaches for Robert Morris University in Moon Township, Pennsylvania. E-mail: $\underline{\text { millerl@ rmu.edu }}$

\section{REFERENCES}

1. B B, E., \& Hammervoll, T. (2010). Cost-based pricing of transportation services in a wholesaler-carrier relationship: An MS Excel spreadsheet decision tool. International Journal of Logistics: Research and Applications, 13(3), 197-210.

2. Coles, S., \& Rowley, J. (1996). Spreadsheet modeling for management decision making. Industrial Management \& Data Systems, 96(7), 17-23.

3. Cory, S. N., \& Pruske, K. A. (2012). Necessary skills for accounting graduates: An exploratory study to determine what the profession wants. Proceedings of the American Society of Business and Behavioral Sciences, 19(1), 208-218.

4. Fischer, M., Albers, S., Wagner, N., \& Frie, M. (2012). Dynamically allocating the marketing budget: How to leverage profits across markets, products, and marketing activities. GfK Marketing Intelligence Review, 4(1), 50-59.

5. Lau, M. A., \& Sugden, S. J. (Eds.). (2011). Applications of spreadsheets in education-the amazing power of a simple tool. Bentham Science Publishers.

6. Ringelstein, D. (2009.) An activity-based costing assessment task: Using an excel spreadsheet. e-Journal of Business Education \& Scholarship of Teaching, 3(1), 25-35. 